\title{
Planning UBD in Horizontal Well to Minimize Formation Damage
}

\section{Ahmed R Al-Bajalan*}

Iraq-Erbil-Koya - Koya technical Institute, Iraq

\begin{abstract}
Underbalanced drilling (UBD) is defined as a condition which generated when effective downhole circulation pressure of the drilling fluid system in touch with reservoir rock is less than presenting formation pressure. Underbalanced drilling (UBD) has been utilized as a mean to eliminate or significantly reduce the problem associated drilling like formation damage which often this problem greatly reduce oil and gas productivity in open hole horizontal well section. The advantage of reduced formation damage results from the fact that the wellbore pressure is intentionally maintained lower than formation pressure during drilling operation. In order to achieve this condition several drilling techniques are used such as aerated drilling, foam drilling which based on low drilling density. In appropriate design or inability to maintain well in underbalanced condition during operation will be potential source of sever invasion damage which linked to several mechanism for damage like spontaneous imbibition, glazing, and macroporosity. Therefore, it is significant to select reservoir candidate carefully, to achieve high profitability.

Furthermore, during UBD formation fluid invade into to wellbore therefore the size and design of surface equipment like separator and reserve tanks are required to handle the produced well fluid. Therefore, the ability to accurately estimate the influx volume and rate of produced fluid is critically significant to size and design surface equipment. In this project a mathematical model has been designed based on rigorous reservoir borehole-cross flow which used to determine the influx volume during UBD and investigate how aerated and foam drilling fluid acts during UBD.
\end{abstract}

Keywords: UBD; Formation damage; Volume of fluid influx

\section{Nomenclature}

Jsp = Specific productivity index, stb/d-psi-ft

$\mathrm{X}=$ distance from toe of drain hole $\mathrm{ft}$

$\mathrm{Xc}=$ critical distance from toe of drain hole, $\mathrm{ft}$

$\mathrm{Dh}=$ borehole diameter, $\mathrm{ft}$

$\mathrm{Dp}=$ drill pipe, in

$\mathrm{Kv}=$ Vertical permeability, $\mathrm{mD}$

$\mathrm{Kh}=$ Horizontal permeability, $\mathrm{mD}$

Iani $=$ permeability anisotropy, dimensionless.

$\Delta p f=$ frictional pressure loss, $\mathrm{psi}$

$\mathrm{Ldr}=$ length of drained hole section, $\mathrm{ft}$

$\Delta l=$ length of increment of Horizontal borehole, $\mathrm{ft}$

$\mathrm{L}=$ total length of drilled Horizontal section, $\mathrm{ft}$

$\mathrm{dh}=$ borehole diameter, in

$\mathrm{dp}=$ drill pipe diameter, in

$\rho \mathrm{m}=$ density of mixture, $\mathrm{Ibm} / \mathrm{ft}^{3}$

$\mu f=$ formation volume factor of reservoir fluid, $\mathrm{rb} / \mathrm{stb}$

$\mathrm{h}=$ formation thickness, $\mathrm{ft}$

$\mathrm{yb}=$ distance of boundary from the borehole, $\mathrm{ft}$

$\mathrm{S}=$ Skin factor, dimensionless

$\operatorname{Pr}=$ reservoir pressure, $\mathrm{psi}$

$\mathrm{pw}(\mathrm{x})=$ pressure in wellbore at $\mathrm{x}$ from the toe, $\mathrm{psi}$

$p_{W H}=$ pressure at heel of Horizontal section, psi

$$
\begin{aligned}
& p_{W T}=\text { pressure at toe of Horizontal section, } \mathrm{psi} \\
& \rho \mathrm{Wo}=\text { injected water density, } \mathrm{kg} / \mathrm{m}^{3} \\
& \varepsilon=\text { equivalent roughness, in } \\
& \varepsilon \text { out }=\text { borehole roughness, in } \\
& \varepsilon i n=\text { commercial steel casing roughness, in } \\
& \mathrm{Ws}=\text { weight flow rate of solid, } \mathrm{Ib} / \mathrm{sec} \\
& \mathrm{Wl}=\text { weight flow rate of liquid } \mathrm{Ib} / \mathrm{sec} \\
& \mathrm{Qg}=\text { volumetric gas injection rate at surface, } \mathrm{scf} / \mathrm{min}
\end{aligned}
$$

\section{Introduction}

International Association of Drilling contractors (IADC) has defined underbalanced drilling (UBD) as a technique in which equivalent circulation density (ECD) of drilling fluid is intentionally maintained less than effective formation rock pressure $(\mathrm{Pf})$ in openhole section at any depth. That results in tendency of fluid to inflow from formation into wellbore.

UBD technique has grown rapidly as alternative technique to conventional drilling (overbalanced) to eliminate or significantly reduce the problem of formation damage in horizontal well.

*Corresponding author: Ahmed R Al-Bajalan, Iraq-Erbil-Koya - Koya technical Institute, Iraq, Tel: 009647505641986; E-mail: Ahmed_nafit@yahoo.com

Received February 28, 2015; Accepted March 16, 2015; Published March 23, 2015

Citation: Al-Bajalan AR (2015) Planning UBD in Horizontal Well to Minimize Formation Damage. J Pet Environ Biotechnol 6: 212. doi:10.4172/21577463.1000212

Copyright: $\odot 2015 \mathrm{Al}-\mathrm{Bajalan} \mathrm{AR}$. This is an open-access article distributed under the terms of the Creative Commons Attribution License, which permits unrestricted use, distribution, and reproduction in any medium, provided the original author and source are credited. 
However, Bennion and Thomas [1] have stated the possibility of existing formation damage in condition where original saturation of hydrocarbon or water in the reservoir is lower than irreducible saturation of the phase that used in drilling. This lead to spontaneous imbibition is caused by capillary pressure and wettability properties. This generally appears in low permeability gas reservoir which has very low initial water saturation.

According to Marbun et al., [2] UBD could be applied in situation where the possibility of severe loss of circulation exists. For instance, highly fracture sandstone reservoir and high permeability vugular carbonate. In addition, UBD was applied in order to increase the penetration rate through reducing "chip hold down" effect which in turn the solid will be removed more easily.

Minimize the pressure on the bit and improve the bit life is another application of UBD since it is reduced the contact with rock and increase penetration rate $[2,3]$. One of the significant reasons for growing underbalanced drilling is that it can improve the financial return on drilling process by increasing the productivity once drilled. Influx of formation fluid during UBD provides an opportunity to evaluate the reservoir in real term, so the fluid properties assessment and geological interpretation can be performed while drilling and optimization can be estimated earlier [2].

As mentioned before, the key principle of underbalanced drilling is keeping downhole pressure less than formation pore pressure. This sometimes occur naturally when unweight fluids are used and the reservoir is geostatically over pressured for its depth [1]. However, several low density drilling fluid techniques have been developed to maintain well in underbalanced condition which generally classified into three main groups:

- Single gas phase such as (Dry air, Nitrogen and Natural gas).

- Single Liquid phase (Flow drilling, Mudcap drilling, lightened drilling).

- Two phase gas - liquid mixture like (Mist drilling, Foam drilling, Aerated liquid).

However, UBD technique has several economical and technical limitations which prevent it implementation in some circumstances. For instance, problem of wellbore instability during UBD which happen once the bottomhole pressure (BHP) is kept lower than pore pressure. Furthermore, prediction the volume and invasion rate of reservoir fluid (oil, water) through UBD might cause difficulty for drilling engineer because of the complicated connection between drilling and formation fluids and rock nature of penetrated formation, practically in the zone around wellbore which have hydraulic and thermal diffusivities between formation and wellbore [3].

\section{Underbalanced Drilling (UBD) Technique}

Underbalance drilling (UBD) can be defined as a drilling technology in which effective hydrostatic head pressure of the circulation drilling fluid system is intentionally designed to be less than the pore pressure of the formations being penetrated. Result in, tendency of formation fluid to flow into borehole (Figure 1).

\section{Motivation of UBD in Horizontal Well}

Once underbalanced drilling designed and executed properly, it can eliminate several problems associated with drilling operation which in turn improves financial return and increase oil and gas productivity. For instance, minimizing formation damage which it is
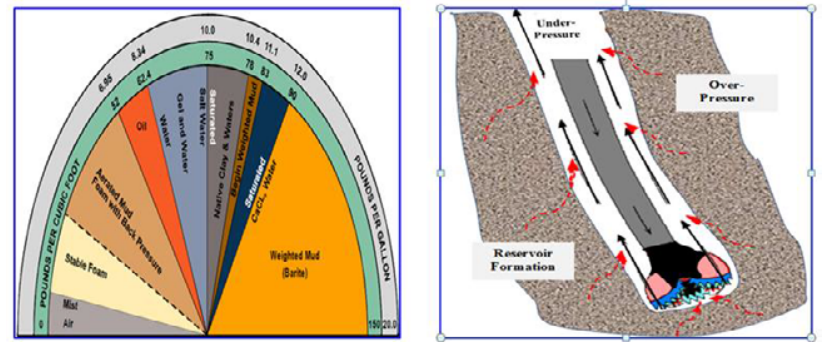

Figure 1: UBD Operationand fluid densities (LEA,2002).

\begin{tabular}{|l|}
\hline \multicolumn{1}{|c|}{ Increased Rate of Penetration (ROP) } \\
\hline Increased bit life \\
\hline Minimized risk of lost circulation \\
\hline Reduced probability of differential sticking \\
\hline Reduced stimulation requirements \\
\hline Ability to flow/well testing while drilling \\
\hline Earlier production \\
\hline Improved formation evaluation \\
\hline
\end{tabular}

Table 1: General advantage associated with UBD.

generally occur when drilling mud invade the rock formation $(\mathrm{Pw}>\mathrm{Pf})$. This physical force impede the stream of reservoir fluid into wellbore; consequently, impair permeability near wellbore [4]. This is especially valid for horizontal well since horizontal section perforates greater producing formation distance and this formation is exposed to drilling fluid for a while. However, from the principle of UBD the pressure of wellbore is less than formation pressure $\left(\mathrm{P}_{\mathrm{w}}<\mathrm{P}_{\mathrm{f}}\right)$ so it can eliminate solid invasion. However, the difficulty here is how to keep the condition in underbalanced mode during the entire drilling process. Generally, the drilling of long horizontal section generates fiction pressure loss in the annulus which effect on bottomhole of the well and gradually increases the geopressure of the formation which result in reducing rate of penetration.

However, the friction loss in the annulus is reduced in UBD by permitting the energy of reservoir to push fluid out of the borehole [5].

In addition, differential pipe sticking is consider one of the major problem in drilling horizontal due to the fact that drilling string lies at the side of bottom hole when drilling bit is being directed or during pipe connection are performed. During such periods, the movement of pipe is less at the bottom hole which would be perfect situation for differential stick occurrence. However, in UBD prevent problem of sticking pipe due to there will be always flow into borehole and filter cake cannot from [6]. Table 1 shows some other benefits that UBD drilling can be provided over conventional drilling (Overbalanced).

\section{Technical Limitation of UBD in Horizontal Well}

Generally, UBD provides several benefits compared to conventional drilling process as illustrated before; however, there are some possible technical limitations associated with this operation when it is not designed and executed properly [6]. Wellbore instability considers as one of the main factor which restrict applying underbalanced drilling in unconsolidated or highly depleted reservoir. This instability comes from mechanically induced due to underbalanced pressure and chemical induced when drilling through formation such as (shale or clay) formation which sensitive to water. These formations might 
dehydrate when drilling with gaseous drilling mud or the possibility of absorbing water when mist, foam or aerated are used as drilling which could lead to well destabilization [2]. According to (Bennion and Thomas) [1], the UBD could be a source of sever formation damage horizontal well due to complexity to keep permanent UBD condition through drilling and completion operation.

\section{Drilling Fluid Selection}

The key principle for successfully drilling underbalanced horizontal well depend on selecting the right drilling fluid system with its phases which provide low density in order to maintain hydrostatic head pressure of the mud ( $\mathrm{Pm})$ below formation pore pressure (Pr). However, improper selection or designing fluid system might cause further formation damage and it also increase the cost of drilling due to downhole fire and corrosion. In order to choose suitable drilling fluid for UBD several factors should be considered such as analyzing petrophysical and geomechanical data, assessment of possible rock damage. The fluid system must design which give BHP less than formation pressure. The ability to transit downhole data should also take into account when selecting fluid system; for instance, gas might reduce bottomhole transmitted signal if used as fluid system. Figure 1 shows different drilling fluid densities.

\section{Selection of UBD Techniques}

\section{Gasified (Aerated) drilling operations}

This type of drilling fluid is commonly used in horizontal well since it optimized to provide better wellbore instability in open hole section because of its higher pressure gradient compared with other drilling fluids. In gasified drilling system, a mixture of gas and liquid are prepared at surface prior it flow into drill pipe or downhole into liquid phase at the annulus [7]. Any available liquid can be used in the mixture as base for liquid phase, but for gaseous phase (nitrogen, air) gases are the common gases are used. However, gas selection is generally depends on downhole explosion tendencies. One of the major advantages of aerated drilling fluid is ability to eliminate or reduce formation damage since it prevent filter cake and filtrates to enters formation, and prevent differential pipe sticking. Therefore, it can be used in formation where lost circulation and formation damage is considered as major concern. In addition, aerated fluid system highly tolerance to high temperature and its densities ranging from 4-7 ppg.

\section{Gasified (Aerated) drilling operations}

This type of drilling fluid is commonly used in horizontal well since it optimized to provide better wellbore instability in open hole section because of its higher pressure gradient compared with other drilling fluids. In gasified drilling system, a mixture of gas and liquid are prepared at surface prior it flow into drill pipe or downhole into liquid phase at the annulus [7]. Any available liquid can be used in the mixture as base for liquid phase, but for gaseous phase (nitrogen, air) gases are the common gases are used. However, gas selection is generally depends on downhole explosion tendencies. One of the major advantages of aerated drilling fluid is ability to eliminate or reduce formation damage since it prevent filter cake and filtrates to enters formation, and prevent differential pipe sticking. Therefore, it can be used in formation where lost circulation and formation damage is considered as major concern. In addition, aerated fluid system highly tolerance to high temperature and its densities ranging from 4-7 ppg.

\section{Lightened drilling technique}

Lightened Drilling fluid can be defined as mixture of two phase gas and liquid in a particular proportion demanded to achieve a desirable density. Lightened drilling fluid can be classified based on structure and proportions of gas-liquid mixture into (mist and foam). Mist drilling fluid like dry air drilling depends on annular velocity of the hole to circulate out the hole. It also provides minimum water influx due to its higher tolerance [8]. Wellbore instability consider as a main concern when using mist drilling due to the high difference in pressure between formation fluid and mist drilling fluid. The chemical and mechanical encouragement wellbore instability is possible specially when drilling unconsolidated or poorly consolidated formation such as shale. The presence of water phase in mist system can cause borehole collapse especially in shale formation since shale it sensitive to water and leads to shale swelling. A rapid corrosion of downhole equipment is another problem which limiting mist drilling, this is due to presence of high level oxygen concentration in mist system which induce steel corrosion (Figure 2).

Although, adding corrosion inhibitor consider as reasonable solution for protecting downhole equipment from corrosion, McLennan et al., find out that the most successful inhibitor for mist drilling system is organo-phosphate ester.

Since water influx is one of the major issues in most types UBD drilling fluid; therefore, adding agents like (foam or surfactant) to the mixed water or gas phases will create foam drilling system. Generally, there is two basic foam systems are used in UBD operations (Stable foam and Stiff foam). These systems have capacity to absorb large quantities of water and provide a better wellbore cleaning. In addition, one of the distinguishing features of foam is that it has high viscosity and low density properties compared with other types of drilling fluids. The high effective viscosity and velocity provide several benefits in term of circulating out large cutting the drilling cutting to the surface and it able to suspend it for a while after stopping circulation [4]. According to Dahl and Bart Vos [8], foam drilling system (Stable foam) is capable to carry out an influx rate of (500 bb/hr). In addition Harris, [9] stated that foam fluid operation displayed as a good candidate for reducing formation damage in the different reservoirs characteristic that has been applied and in different well types.

\section{Underbalance Reservoir Screening and Selection}

Technically, UBD is almost feasible in all situations. However, it is essential prior starting UBD set of reservoir criteria should be taken into consideration which helps to determine whether specific reservoir

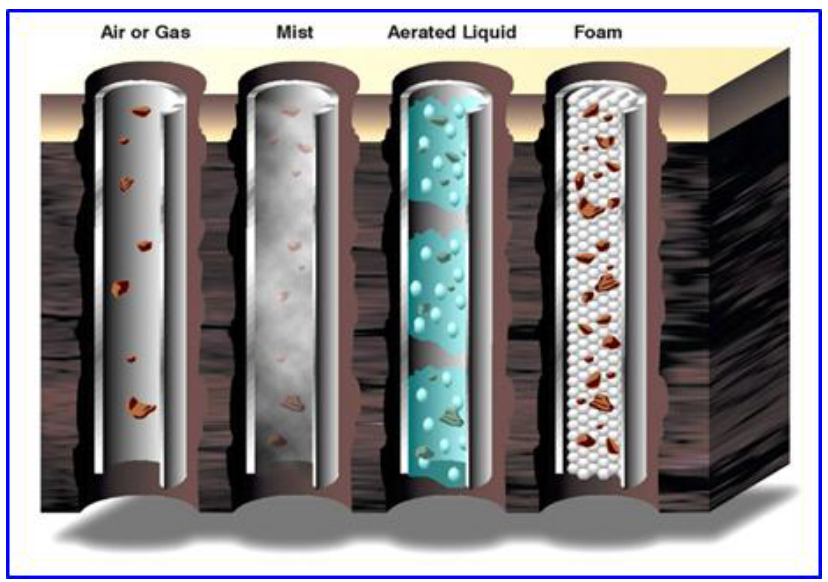

Figure 2: Compressible drilling fluids technologies (Weatherford,2002) 
is prime candidate for underbalanced drilling. The Table 2 below based on several previous studies which shows acceptable characteristic for a reservoir to be drilled underbalanced, it also include some unacceptable reservoir indication for UBD [6,9]. Table 3 shows some good candidate for implementing UBD.

\section{Mechanism of Formation Damage in Horizontal Wells (Drilling)}

Formation damage considers as a complex phenomenon which caused by several mechanism and generally depending on reservoir characteristic, formation lithology and kind of drilling. Although there are several damage phase exist, a common mechanism which trigger the formation damage in horizontal as follow:

\section{Fines migration}

This indicates to mobilization of in-situ fine particles within formation. This movement strongly associated with formation wettability. Generally, this movement tends to be problematic in clastic formation because of higher concentration of mobile materials. In such situations UBD would be utilized to minimize particles migration during drilling and clean -up operations [5]. However, the only possible problem associated with this issue during UBD, if adequate UB pressure present and the high production flow from formation represent the wetting phase. This might lead to early initiation of fine mobilization [10]. These fine particles will build bridge across pore throat which reduce well productivity.

\section{Phase trapping/blocking}

This happen due to invasion of drilling fluid oil and water phase into porous medium near to horizontal wellbore region due to several factors like difference between initial water saturation and irreducible water saturation during underbalanced drilling and leak off during overbalanced drilling. This phenomenon could result in constant entrapment of whole or portion of the fluid influx which result in minimize of oil and gas permeability due to adverse relative permeability effect (Figure 3).

\section{Chemical incompatibility of invading fluid (Reactive clay)}

Several formations include potentially in situe reactive clay structure like smectite or kaolinite which are susceptible to hydration or deflocculation (clay particles are broken) conditions either by contacting with low salinity water or sudden salinity switch [1]. The

\begin{tabular}{|l|}
\hline \multicolumn{1}{|c|}{ Downhole (Bottomhole) fire } \\
\hline Conventional MWD is ineffective when compressible fluid are used \\
\hline Poorly managed multiphase flow could create drilling problem. \\
\hline Possible excessive borehole erosion \\
\hline
\end{tabular}

Table 2: General disadvantages of UBD. scattered particles tend to plug pore throat. The encouragement of UBD is to reduce the losses of possibility damaging incompatible liquid flowing into formation which tends to create a region near wellbore which is highly permeability deteriorated (Figure 4).

\section{Biological activity (Bacteria)}

The bacteria agents (aerobic and anaerobic) which might present in water based fluid which can enter region near wellbore and result in creation of polysaccharide bacteria that consider as waste and reduce near wellbore permeability. UBD can be used to avoid long term losses drilling fluid which might contain viable population of bacteria.

\section{Potential Mechanism of Formation Damage during UBD}

Generally, there are several ways in which formation damage could occur during drilling horizontal well such as fine migration, phase trapping, and effect of institute fluid and invading fluid. However, there is also number of possible damage mechanisms associated with underbalanced drilling these include the following.

\section{Lack of potential sealing cake}

With appropriate UB drilling operation, the classic bridge filter cake on the surface of the rock is not established due to fluid flowing from formation into borehole and the drilling fluids do not contain any bridging agent. In addition, the complexity to totally maintain drilling in underbalanced condition from the commencement of drilling to the completion stage. This is due to drilling unexpected under pressure

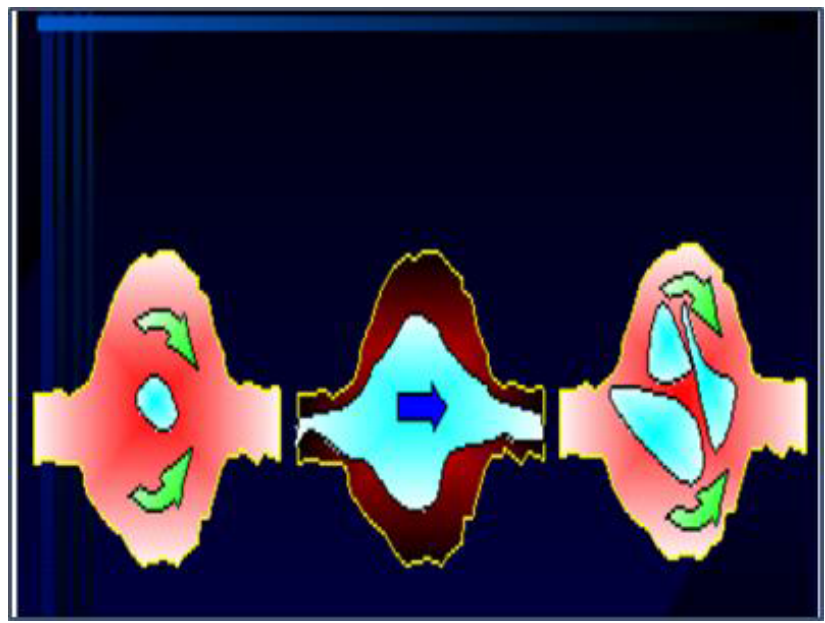

Figure 3: Fine migration and phase trapping mechanisms (Rafique 2008).

\section{Reservoir suitable from UBD}

Under pressure/depleted formation or mature field.

Dehydration formations exhibiting subirreducible water saturation or hydrocarbon saturation.

High permeability (>1000 md) consolidated intercrystalline sands and carbonates.

Formations containing significant concentrations of water-based mud filtratesensitive material (clays $>1 \%$ ), anhydrite.

Hard rock formation because of well bore stability.

\section{Reservoirs generally will not suitable from UBD}

High pressure zones exhibiting high flow and potential control problem.

High pore pressure coupled with highly permeable formation

Formation susceptible to spontaneous imbibition

Hole section with various pressure.

Formation where reservoir knowledge is poor

Table 3: Reservoir aspect during UBD. 


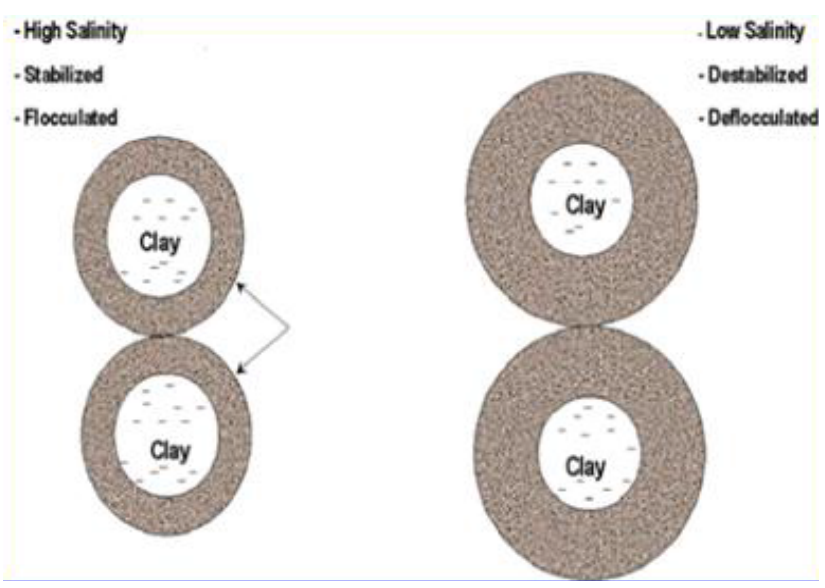

Figure 4: Clay flocculated and deflocculated mechanisms (Qutob, 2004).

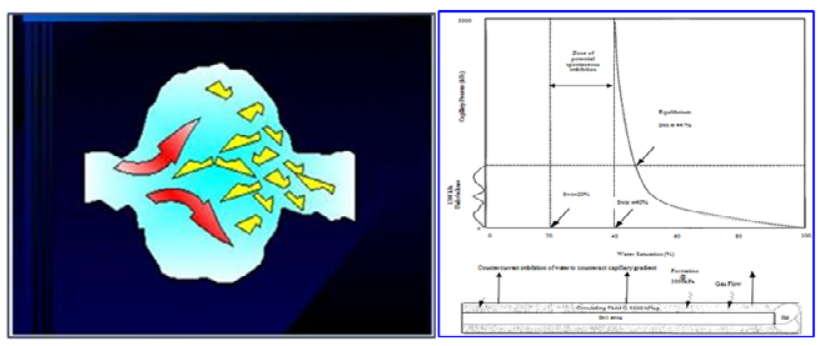

Figure 5: Spontaneous imbibition in UBD (Bennion and Thomas, 1994).

zone, and mechanical or technical trouble which leads to stop of gas pumping $[1,11]$.

\section{Spontaneous imbibition and counter current imbibition}

This effect occur in situation where initial saturation of hydrocarbon or water is less than irreducible saturation of the drilling fluid phase then the capillary pressure $(\mathrm{Pc})$ and wettability will cause spontaneous countercurrent imbibition. It is potential for water based or hydrocarbon based fluids to imbibe into reservoir nearby wellbore zone which give rise to minimizing the permeability due to incompatibility influence of rock -fluid or fluid -fluid. This phenomenon will cause the formation matrix to saturate with water by itself. The severity level of countercurrent imbibition is function of initial water saturation (Swi) and Irreducible water saturation (Swir) at capillary pressure (PC), when PC curve becomes close to vertical as shown in Figure 5 [1]. In addition, the seriousness of formation damage associated is highly relying on configuration of relative permeability curve for gas phase in low liquid saturation region.

\section{Macroporosity gravity induced invasion}

If a large interconnected vugs or fracture (macroporosity) formation have drilled horizontally, the lower side of horizontal well will be invaded by drilling fluid and solid due to gravity force as shown in the Figure 6. This phenomenon is a function of underbalanced pressure. When a very large porous formation is drilled at lower underbalance pressure, the fluid superficial velocity will be minimized. As a result, the drilling fluid and solid invade these features, even though the condition is kept underbalanced.

\section{Glazing and mashing damage}

Glazing is a polishing of the external surface of wellbore which occurs in pure gas drilling due to lack of heat conductive capacity of drilling fluid to cool and lubricate drilling bit face. The glazing problem often severe when high gas injection rate is used for hard formation at low rate of penetration. This problem does not appear in parasite or concentric string. However, when the formation face polished by inappropriately drilling string centralizing mashing mechanism damage will appear. The depth of potential damage caused by glazing and mashing tend to be shallow. The most formation susceptible to this damage is homogenous formation.

\section{Economical and Environmental Evaluation of UBD}

Generally, UBD technology is demanded by most petroleum producer company since this technique improving the financial return on drilling well. This improvement comes from the various benefits that provided [12]. Even if the cost of drilling well by UBD is increased, preventing formation damage could increase oil and gas productivity which in turn net present value (NPV) of the well will increase.

However, in some cases this technique is considered as an expensive technique compared with conventional drilling particularly when drilling well horizontally. For example, using nitrogen gas as drilling fluid to drill extended reach open hole horizontal section would be costly because of required volume of nitrogen for drilling. However, a portion of this expense may be offset by the benefit which is provided like increase ROP which result in save rig time if the well drilled completely in underbalance fashion. In addition, an alternative cheap gasification medium such as air can be used but it requires careful monitoring to avoid downhole combustion [1]. Furthermore the cost of drilling a well by UBD varies depending on the reservoir that is faced and the type of produced reservoir fluid since it requires special surface separation equipment. The number of drilled well and location of well have direct impact on mobilization cost.

During execution UBD significant volume of fluids is produced during UBD and due to combustible properties of these products a great attention must be paid into safety and environmental issues. In order to avoid hazards of explosion, the orientation of hydrocarbon separation and storage should take into consideration by position against wind. However, closed loop systems can be used in underbalanced drilling, so the potentially of produced waste drilling fluid would be less and provides additional environmental protection over drilling operation.

\section{Formation Fluid Invasion}

\section{Mathematical model}

The following mathematical equations have been used to achieve the aim of this project. The formation liquid influx rate equation which have been driven by Guo, Xiaodong has been used [2]. This equation is based on integrating the influx volume over total period for horizontal well. Figure 7 illustrates horizontal borehole cross flow that used for deriving the following equation [Appendix]

$$
\mathrm{Q}_{\mathrm{f}}(\mathrm{x})=\frac{\mathrm{J}_{\mathrm{sp}}}{2 \mathrm{~b}}\left[\frac{1}{\mathrm{a}^{2}}-\frac{1}{a+b x^{2}}\right]
$$

Qf(x): flow rate at $(x)$ location (stb/d), L: horizontal borehole section length ( $\mathrm{ft}$ ) and the intermediate parameter (a,b, C and $\left.\mathrm{C}^{\prime}\right)$ equations are : 


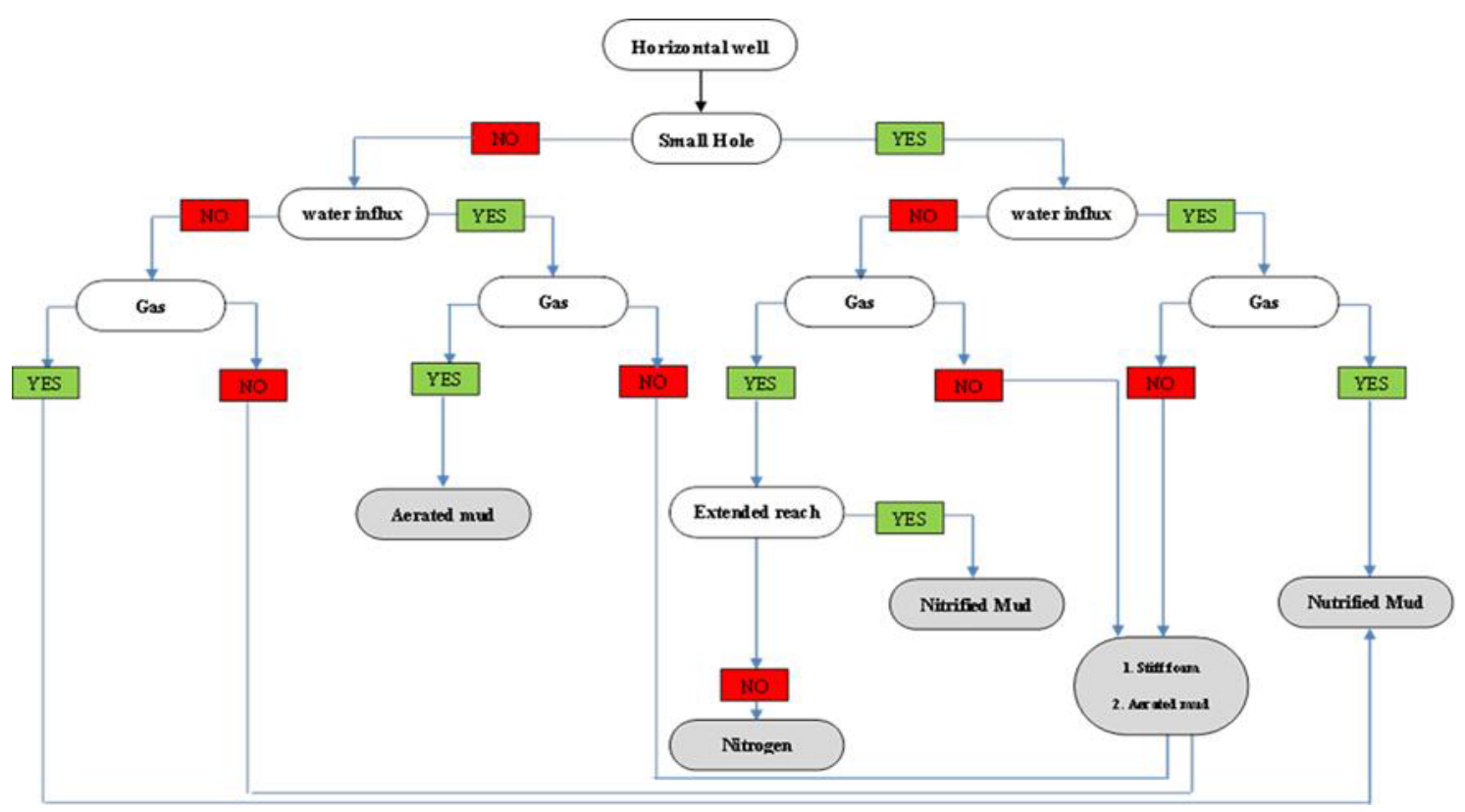

Figure 6: Selection of UBD fluid in horizontal well.
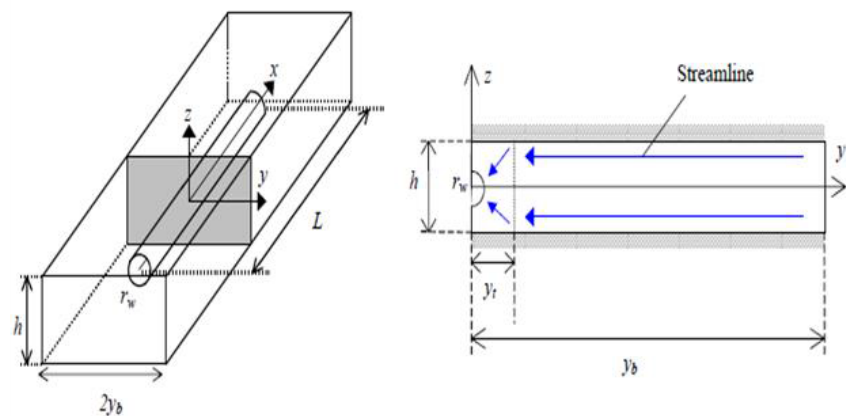

Figure 7: Flow geometry of Horizontal well (Rectangular reservoir).

$$
\begin{aligned}
& \mathrm{a}=\frac{1}{\sqrt[3]{P r-P w H}}+0.2752 C^{2 / 3} L \\
& b=-0.2752 C^{\frac{2}{3}} \\
& C=\frac{2 C^{\prime}}{\sqrt{\frac{6 g c(d h-d c)}{\mathcal{F} f \rho}}} \\
& \mathrm{c}^{\prime}=\frac{0.012 J s p}{\left(d h^{2}-d p^{2}\right)}
\end{aligned}
$$

The influx rate equation is based on assumption that reservoir flow pattern is turbulent and flow rate of produced fluid increase from toe to heel sections and reach to critical value which known as critical flow rate (Qoc) which is ignored.

In addition, specific productivity index (Jsp) was selected based on reservoir fluid flow conditions which in turn depend on horizontal sections penetrations

$$
\begin{aligned}
& \mathrm{J}_{s p}=\frac{7.08^{* 1} 0^{-3} \mathrm{kh}}{\mu_{f} B_{f}\left\{\mathrm{I}_{a n i} \ln \frac{2 \mathrm{~h}}{\mathrm{D}_{h}(\mathrm{Iani}+1)}+\frac{\pi \mathrm{yb}}{\mathrm{h}}-\mathrm{I}_{a n i}(1.224-\mathrm{S})\right\}}, \\
& I_{a n i}=\frac{\sqrt{k h}}{\sqrt{k v}} .
\end{aligned}
$$

\section{Results and Discussion}

It is obvious that during drilling a well horizontally by underbalanced drilling technique the bottom -hole pressure maintained below formation pore pressure. From this concept the fluid will flow from formation into bore hole. Therefore, it is necessary to have an estimation or prediction about the volume and the rate of liquid inflow into to the well. The result of liquid inflow rate and cumulative liquid influx volume computation for $(600 \mathrm{ft})$ length of horizontal section are shown in the Figure 8 below. The input data is shown in Table 4. It is clear that from the Figure 9, the peak of inflow rate will be $\left(367 \mathrm{ft}{ }^{3} / \mathrm{hr}\right)$ $(45 \mathrm{gpm})$ and cumulative inflow rate $\left(4089 \mathrm{ft}^{3}\right)$ at the end of horizontal section. Therefore, it is necessary to design a separator which can treat 

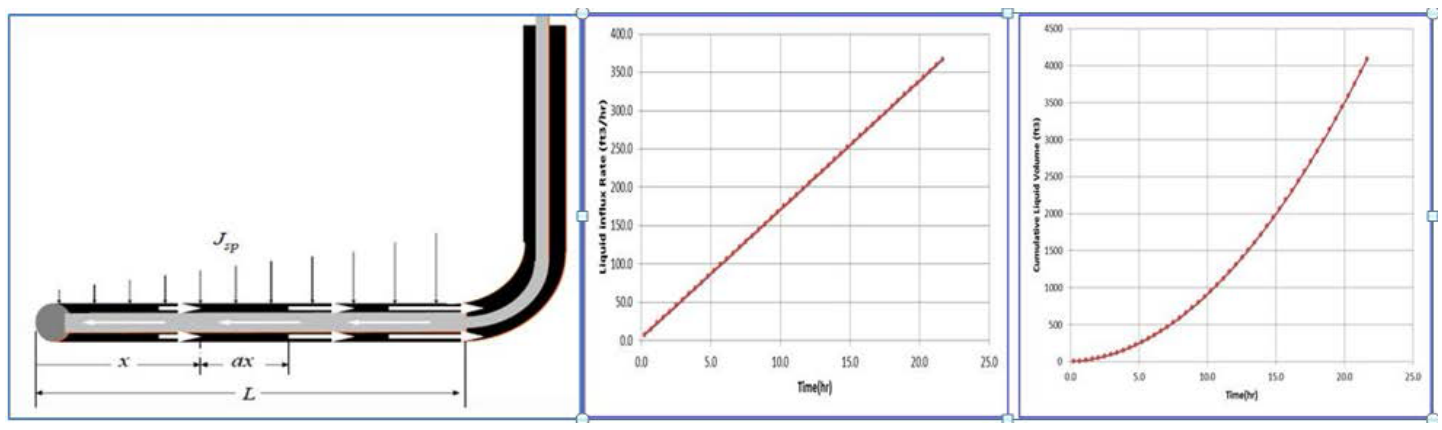

Figure 8: 9-Liquid influx rate and volume at end of horizontal section.

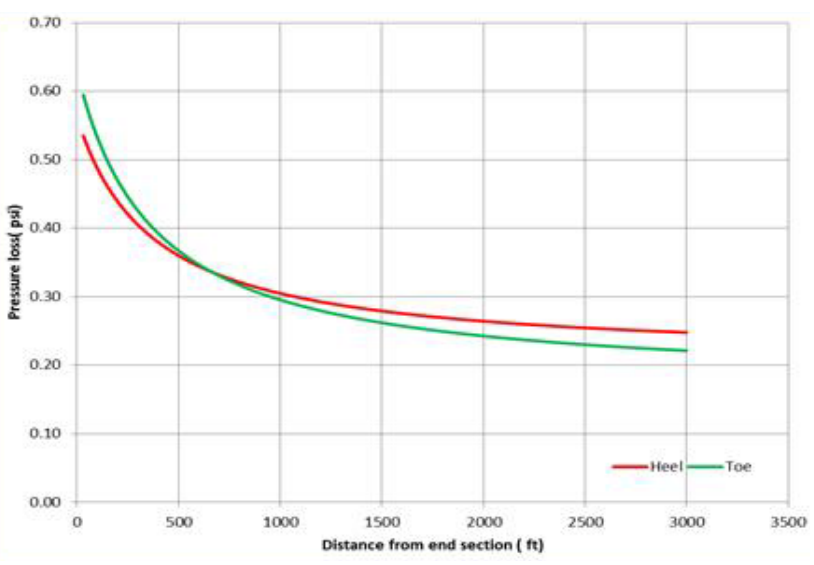

Figure 9: Pressure loss distribution along heel and toe sections.

\begin{tabular}{|c|c|c|c|c|c|}
\hline Pay Zone Thickness (h) & 48 & $\mathrm{ft}$ & Reservoir Pressure & 5035 & psi \\
\hline Horizontal Permeability (Kh) & 54 & $\mathrm{md}$ & Bore Hole diameter & 7.875 & in \\
\hline Vertical Permeability (Kv) & 19 & $\mathrm{md}$ & Drill pipe diameter & 4.5 & in \\
\hline Skin Factor (s) & 0 & & Borehole length & 600 & $\mathrm{ft}$ \\
\hline Fluid Viscosity $(\mu)$ & 0.5 & $\mathrm{cp}$ & Borehole roughness & 0.05 & in \\
\hline Fluid formation volume factor (Bf) & 1.15 & $\mathrm{rb} / \mathrm{stb}$ & Boundary Distance(yb) & 2000 & $\mathrm{ft}$ \\
\hline Fluid density $(\rho f)$ & 51 & $\mathrm{lb} / \mathrm{ft} 3$ & Penetration Rate (Rp) & 27.69 & $\mathrm{ft} / \mathrm{hr}$ \\
\hline UB drowdown pressure & 535 & psi & & & \\
\hline
\end{tabular}

Table 4: Reservoir input data.
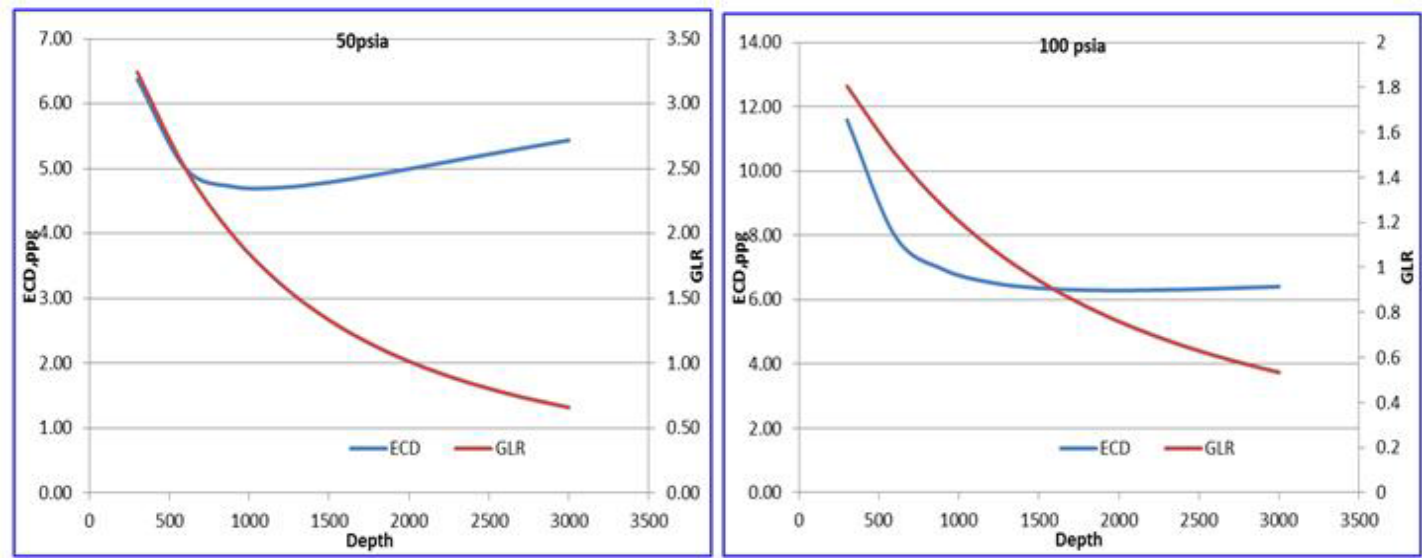

Figure 10: Effect of choke pressure on ECD and GLR. 

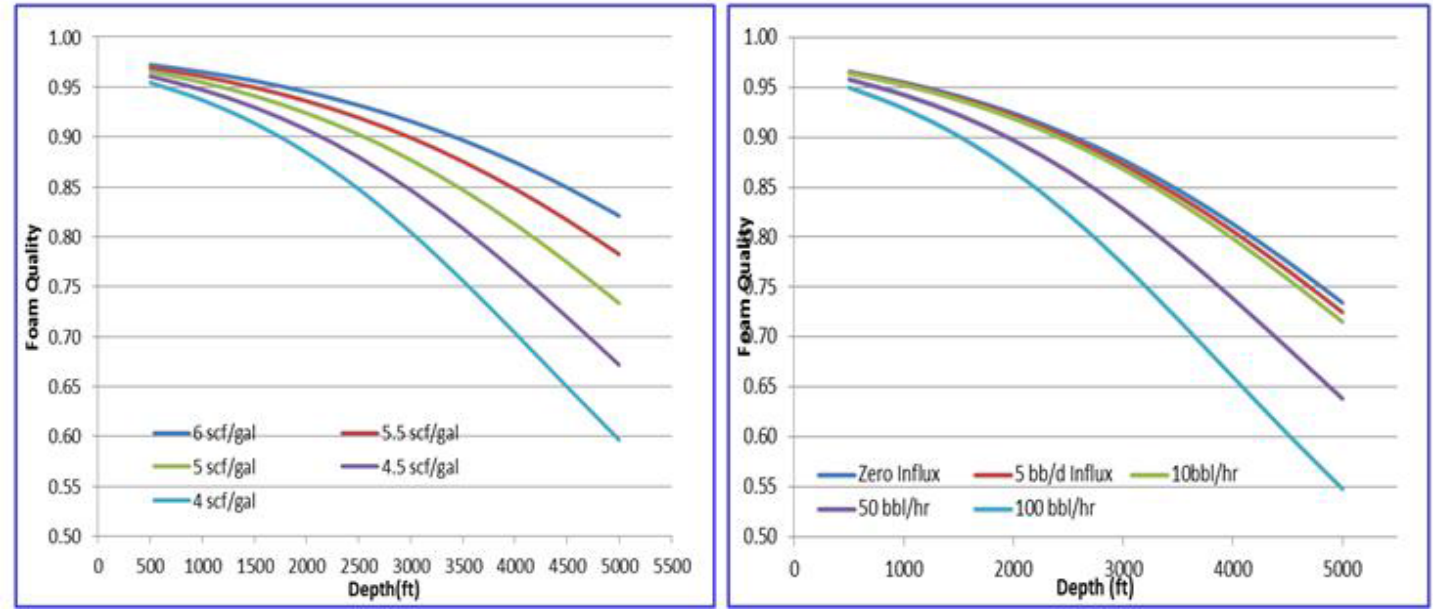

Figure 11: Effect of influx and gas injection on foam quality.

\begin{tabular}{|c|c|c|c|}
\hline Time (hr) & $\begin{array}{l}\text { Horizontal } \\
\text { penetration (L) }\end{array}$ & $\begin{array}{l}\text { Liquid Influx rate } \\
\text { (ft3/hr) }\end{array}$ & $\begin{array}{l}\text { Cumulative influx } \\
\text { volume (ft3) }\end{array}$ \\
\hline 0.2 & 7.6 & 7.6 & 1.6 \\
\hline 0.7 & 15.2 & 15.2 & 8.6 \\
\hline 1.1 & 22.8 & 22.8 & 19 \\
\hline 1.6 & 30.4 & 30.4 & 32.8 \\
\hline 2 & 38 & 38 & 50.2 \\
\hline 2.5 & 45.6 & 45.6 & 71 \\
\hline 3 & 53.2 & 53.2 & 95.2 \\
\hline 3.4 & 60.8 & 60.8 & 123 \\
\hline 3.9 & 68.5 & 68.5 & 154.2 \\
\hline 4.3 & 76.1 & 76.1 & 188.9 \\
\hline 4.8 & 83.7 & 83.7 & 227 \\
\hline 5.2 & 91.3 & 91.3 & 268.7 \\
\hline 5.7 & 98.9 & 98.9 & 313.8 \\
\hline 6.1 & 106.5 & 106.5 & 362.4 \\
\hline 6.6 & 114.2 & 114.2 & 414.4 \\
\hline 7.1 & 121.8 & 121.8 & 470 \\
\hline 7.5 & 129.4 & 129.4 & 529 \\
\hline 8 & 137.1 & 137.1 & 591.5 \\
\hline 8.4 & 144.7 & 144.7 & 657.5 \\
\hline 8.9 & 152.3 & 152.3 & 726.9 \\
\hline 9.3 & 160 & 160 & 799.9 \\
\hline 9.8 & 167.6 & 167.6 & 876.3 \\
\hline 10.2 & 175.2 & 175.2 & 956.2 \\
\hline 10.7 & 182.9 & 182.9 & 1039.6 \\
\hline 11.2 & 190.5 & 190.5 & 1126.5 \\
\hline 11.6 & 198.2 & 198.2 & 1216.5 \\
\hline 12.1 & 205.8 & 205.8 & 1310.7 \\
\hline 12.5 & 213.5 & 213.5 & 1408.1 \\
\hline 13 & 221.1 & 221.1 & 1508.9 \\
\hline 13.4 & 228.8 & 228.8 & 1613.2 \\
\hline 13.9 & 236.4 & 236.4 & 1721.1 \\
\hline 14.4 & 244.1 & 244.1 & 1832.4 \\
\hline 14.8 & 251.8 & 251.8 & 1947 \\
\hline 15.3 & 259.4 & 259.4 & 2065.5 \\
\hline 15.7 & 267.1 & 267.1 & 2187.3 \\
\hline 16.2 & 274.7 & 274.7 & 2312.5 \\
\hline 16.6 & 282.4 & 282.4 & 2441.3 \\
\hline
\end{tabular}

\begin{tabular}{|l|l|l|l|}
\hline 17.1 & 290.1 & 290.1 & 2573.6 \\
\hline 17.5 & 29.8 & 29.8 & 2709.4 \\
\hline 18 & 305.4 & 305.4 & 2848.6 \\
\hline 18.5 & 313.1 & 313.1 & 2991.4 \\
\hline 18.9 & 320.8 & 320.8 & 3137.7 \\
\hline 19.4 & 328.5 & 328.5 & 3287.5 \\
\hline 19.8 & 336.2 & 336.2 & 3440.8 \\
\hline 20.3 & 343.9 & 343.9 & 3597.6 \\
\hline 20.7 & 351.6 & 351.6 & 3757.9 \\
\hline 21.2 & 359.3 & 359.3 & 3921.7 \\
\hline 21.6 & 367 & 367 & 4089.1 \\
\hline & Table 5: Results of Mathematical Influx prediction. \\
\hline
\end{tabular}

this rate of influx and the tanks should be chosen to handle $4089 \mathrm{ft}^{3}$ of the produced liquid (Figure 10).

Figure 11, shows pressure loss distribution along each section and it is clear that the pressure loss near the toe is higher than heel this is due to turbulence flow at the end section of horizontal well because the drilling fluid pumping path through drilling string into annulus. There is a slightly pressure decrease around heel section. It is necessary to have an estimation value about the amount of injection gas required for drilling horizontal well by UBD (Table 5).

It is also discovered that different choke pressure (50 Pisa) and (100 Pisa) at constant gas and mud injection rate (300 scfm and $150 \mathrm{gpm}$ ) could effect on Equivalent circulation density (ECD). It is clear that with increasing surface pressure the equivalent circulation density increase from (5.44 to 6.4 at $3000 \mathrm{ft}$ ). This should be taken in consideration when selecting casing depth to prevent formation breakdown. In addition, this project has find out that how formation influx could impact on in situ foam quality. It is obvious from the Figure below that by increasing influx rate the foam quality reduced. Generally, typical foam quality range from (0.55-0.97), if it goes above this rage the foam structure become unstable and foam turn to mist. The foam quality also is influenced by the rate of gas liquid ratio injection. By reducing this ratio the foam quality is reduced as shown in the Figure 11 and (Table 6).

\section{Conclusions}

Several potential damages could appear during UBD such as spontaneous imbibition (generally occur when initial reservoir 


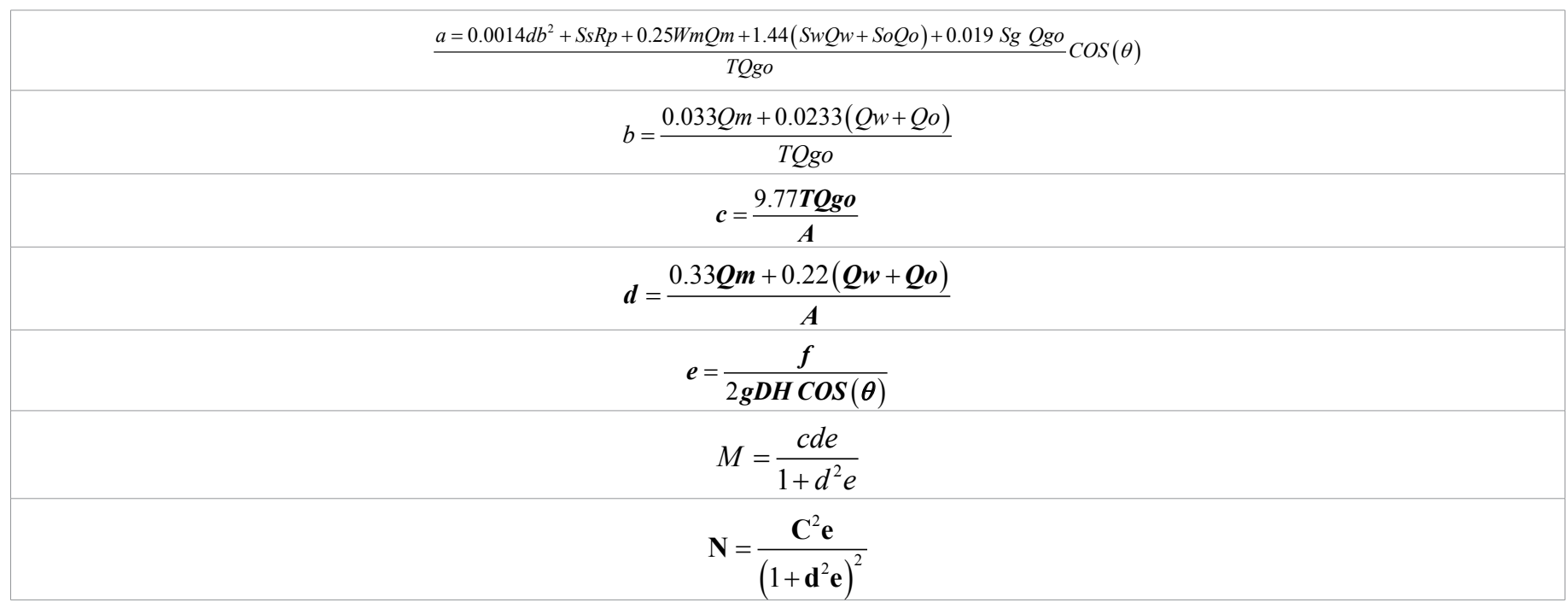

Table 6: Aerated mathematical equations.

saturation is less than irreducible saturation of drilling fluid phase), glazing and mashing, macroporosity due to improperly designing and executing UBD program. It is also necessary to continuously monitor and adjusted the UBD draw-down as required in order to handle the quantities of produced fluid while drilling and ensure small liquid gains during process.

It is concluded that, in some period the pressure at end section of horizontal well will reach to formation pressure due to losses of the fictional pressure across borehole. Therefore, it can be seen overbalance condition in the toe section while heel section remains underbalanced. It became obvious during pipe connection process some inflow occurs since the drilling fluid is not pumped down during this process. The volume of the influx during pipe connection could be even higher as a result of lower BHP at this time.

\section{Recommendations}

This study is carried out based on mathematical model in order to achieve its aim due to unavailability of software which can deal with UBD in horizontal well. In addition due to time limitation, the recommendation and suggestion for further study and research in such field are:

Perform experimental study to find out how effective underbalanced drilling for removing formation damage in dual lateral horizontal well.

Find out the effect of pressure distribution on liquid formation volume factor across borehole.

Take into account rate of penetration rate as function of wellbore pressure.

\section{Acknowledgment}

I would like to express my sincere appreciation to my supervisor Dr. Jim Somerville, for his guidance, assistance, and great suggestions during the progress of this work. Also, his encouragement and valuable advice are highly appreciated.

I would like to take this opportunity to thank all those who have contributed any way to finalise of this project. I gratefully acknowledge financial support from the Kurdistan Regional government to finish MSc. Petroleum engineering at Heriotwatt University.

\section{References}

1. Bennion D, Thomas F (1994) Underbalanced Drilling of Horizontal Wells: Does It Really Eliminate Formation Damage? Society of Petroleum Engineering,
Symposium on Formation Damage Control, Lafayette, Louisiana, UK.

2. Marbun B, Sinaga SHI, Gaol C (2012) A methodology of Underbalanced drilling design in depleted reservoir. Society of Petroleum Engineering, International Petroleum Technology Conference, Bangkok, Thailand.

3. Guo B, Shi X (2007) A Rigorous Reservoir Wellbore Cross - Flow Equation for Predicting Liquid Inflow Rate During Underbalanced Horizontal Drilling Society of Petroleum Engineering, Asia pacific Oil and gas conference, Jakarta, Indonesia 1-5.

4. Ramelho J (2002) Underbalance Drilling Primer, Shell International and production, Rijswijk, Netherland.

5. Leading Edage Advantage (2002) Introduction to Underbalanced drilling, Aberdeen: LEA.Ltd.

6. Bennion D, Thomas F, Jamaluddin A (2000) Using Underbalanced Drilling to Reduce Invasive Formation Damage and Improve well Productivity-An Update. Journal of Canadian Petroleum Technology 39: 7.

7. Pathak P (2010) Underbalanced Operation. Master Thesis: Petroleum University, Pandit Deendayal, India.

8. Dahl T, Vos B (1999) Underbalanced Drilling Manual: Houston: Baker Hughes Incorporated: version 10 .

9. Harris P (1992) Application of Foam Fluid to Minimize Damage during Fracturing. Society of Petroleum Engineering, International meeting on Petroleum Engineering, Beijing, China.

10. Frick T, Economides M (1991) Horizontal Well Damage Characterization and Removal. Society of Petroleum Engineering. Journal of production and facilities.

11. Bennion D, Lunan B, Sapong AJ (1998) Underbalanced drilling and completion Operation to Minimise Formation Damage-Reservoir Screening Criteria for Optimum Application. Journal of Canadian Petroleum Technology 37: 36-60.

12. Guo B, Jinkui Z, Ying L, Ghalamor A (2007) A Rigorous Analytical Model for Fluid Flow in Drainholes of Finite Conductivity Applied to Horizontal and Multilateral Wells. Society of Petroleum Engineering, Production Operation Symposium, Oklahoma, USA. 